\title{
Mental Health in the Mexican Armed Forces
}

\author{
Angel Alberto Ruiz-Chow, Javier Nicolas Zepeda de Alba²
}

Ex jefe de Salud Mental del Centro Médico Naval, 2007-2017. Médico adscrito a la Subdirección de Psiquiatría del Instituto Nacional de Neurología y Neurocirugía MVS. Vicepresidente PMG, Centro Médico ABC.

2 Capitán de Navío del Servicio de Sanidad Naval, Director General Adjunto de Sanidad Naval. SEMAR.

Correspondence:

Angel Alberto Ruiz-Chow

Subdirección de Psiquiatría

Instituto Nacional de Neurología y

Neurocirugía MVS

Insurgentes Sur 3877

Col. La Fama, Tlalpan, 14269

Ciudad de México. México.

Phone: +52 (55) $5502-2820$

Email: aaruizchow@gmail.com

Citation:

Ruiz-Chow, A. A, \& Zepeda de Alba, J. N. (2020). Mental Health in the Mexican Armed Forces. Salud Mental, $43(2), 55-56$

DOI: $10.17711 /$ SM.0185-3325.2020.008
The Mexican Armed Forces comprise the National Defense Secretariat and the Navy Secretariat (SEMAR). Their mission is to use the power of the Federation for national defense, contribute to internal security, undertake civic actions and social works that advance the progress of the country, protect people's assets in the event of disaster, and reconstruct the areas affected, in accordance with the Political Constitution, the laws that derive from it and international treaties. Personnel admitted to the Armed Forces as military personnel (soldiers and marines) are Mexicans by birth recruited through a continuous system and evaluated prior to admission as regards their bodily, and mental, and physical health skills. Once on active duty, they undergo an annual assessment. In recent years, in SEMAR this annual medical examination has specifically included aspects of mental health to determine the effect of the functions performed by military personnel on the former. Guidelines are issued by the Naval Health Division to undertake specific detection and care programs for various mental disorders such as post-traumatic stress disorder and affective and psychotic disorders.

Various armies throughout the world have evaluated mental health in troops deployed in armed conflict situations. Due to its proximity to our country, our main source of comparison is the United States. Studies have found that suicide is the tenth leading cause of death for all ages in the general population of the USA, but the second leading cause of death in young adults (Roy-Byrne, 2013). Every 13 minutes, someone dies from suicide (Gold, Sen, \& Schwenk, 2013), which is therefore a major problem in the military population (Stein, \& Ursano, 2013). More soldiers died from suicide than in combat (AFHSC, 2012a; AFHSC 2012b) and eighteen American war veterans die every day from suicide (Kemp, \& Bossarte, 2013). The University of Hawaii (Smith, Doidge, Hanoa, \& Frueh, 2019), together with the US Department of Defense, counted the number of suicides reported in the army across a 200 -year period beginning in 1843. An upward trend was observed in annual suicide rates in active members of the US Army, reaching a maximum rate of 118.3 per 100,000 in 1883 . Thereafter, rates decreased by three historical points at the end of the following wars: the Spanish-American War (1898), World War I (1914-1918), and World War II (1939-1945) By the end of this war, the historical rate was the lowest ever -five deaths/100,000 active military personnel between 1944 and 1945. Rates stabilized during the Cold War (19451991) to a frequency of 10-15/100,000. The rate increased again in the Afghanistan and Iraq wars, rising to $29.7 / 100,000$ in 2012 , where it has remained until today.

As a result of these findings, the authors suggest that the US military is not isolated from social, cultural, or economic changes. We can assume that the same applies to Mexican armed forces. Another study was carried out, albeit on a smaller scale (Ursano et al., 2020) with the aim of examining the associations between the sociodemographic characteristics, lifestyles, and stressors of the past year in deployed servicemen (time spent in the area of war operations and armed confrontations) and mental disorders. In addition, the association with suicide ideation (SI) was explored, asking respondents whether this idea was present in the past 30 days in a US Army sample deployed in Afghanistan. The authors justified this study on the grounds that most of the knowledge available to date on mental health and suicide risk in American soldiers is based on studies conducted after deployment. Very few studies examine suicide ideation and mental disorders during deployment. In the study 
conclusions, the authors report finding an increase in suicide attempts among soldiers who had suicide ideation in the last 30 days halfway through their deployment. A group of soldiers with SI had no mental disorders and are a group of interest for identifying other risk and protection factors. Risk factors for greater SI included traumatic events in the past. Interestingly, this is also known as a risk factor for developing posttraumatic stress. They also found major depressive disorder as a factor associated with the presence of suicide ideation.

Mental health research using data from military populations makes it possible to construct valuable study models: in deployment situations, the military remains under very similar environmental, time, food, work, social, and physical activity conditions. They are also exposed to the same combat stressors, making it easier to observe variables associated with the development of disorders such as post-traumatic stress, major depression, suicide attempts, and suicide ideation.

In Mexico, since the military and naval health system encompasses the entire country, population studies may be of great interest in the development and implementation of public mental health policies based on more precise measurements, and can help us understand many mental health phenomena not only in the military but also in the general population. At the same time, military personnel's lifestyle confers other risks the general population does not face, such as continuous changes of address and long absences from the family group. Recent years have seen a new phe- nomenon in the Mexican armed forces: the incorporation of female heads of household or with other family conditions of interest for social research. In conclusion, research undertaken within armed institutes and inter-institutionally to determine various aspects of mental health in the Mexican military is of enormous national interest.

\section{REFERENCES}

Armed Forces Health Surveillance Center (AFHSC). (2012a). Deaths by suicide while on active duty, active and reserve components, US Armed Forces, 19982011. MSMR, 19(6), 7-10.

Armed Forces Health Surveillance Center (AFHSC) (2012b) Injuries due to firearms and air guns among U.S. military members not participating in overseas combat operations, 2002-2011. MSMR, 19(9), 2-6.

Gold, K. J., Sen, A., \& Schwenk, T. L. (2013). Details on suicide among US physicians: data from the National Violent Death Reporting System. General Hospital Psychiatry, 35(1), 45-49. doi: 10.1016/j.genhosppsych.2012.08.005

Kemp, J., \& Bossarte, R. (2013). Suicide data report: 2012. Washington, DC: Department of Veterans Affairs, Mental Health Services, Suicide Prevention Program.

Roy-Byrne, P. (2013). Suicide: the long and winding road from research to practice. Depression and Anxiety, 30(10), 893-895. doi: 10.1002/da.22181

Smith, J. A., Doidge, M., Hanoa, R., \& Frueh, B. C. (2019). A historical examination of military records of US Army suicide, 1819 to 2017. JAMA Network Open, 2(12), e1917448. doi: 10.1001/jamanetworkopen.2019.17448

Stein, M. B., \& Ursano, R. J. (2013). Suicide among United States military personnel: Determining the root causes [Editorial]. Depression and Anxiety, 30(10), 896897. doi: $10.1002 /$ da.22196

Ursano, R. J., Mash, H. B. H., Kessler, R. C., Naifeh, J. A., Fullerton, C. S., Aliaga, P. A., ... Gonzalez, O. I. (2020). Factors associated with suicide ideation in US Army soldiers during deployment in Afghanistan. JAMA Network Open, 3(1), e1919935. doi: 10.1001/jamanetworkopen.2019.19935 